RU Соотношение между знаковыми системами: вербальный и изобразительный языки (на примере «Салонов» Дени Дидро)

\author{
Белова Т. М.
}

\begin{abstract}
Аннотация. Цель исследования - определить соотношение между вербальным и изобразительным языками на примере литературных комментариев Дени Дидро к произведениям искусства. В статье дается характеристика критических очерков, так называемых Салонов. Полученные данные позволяют прийти к заключению, что салоны Дидро выполняют определенные функции, с одной стороны, они влияют на общественное мнение и формируют мораль, с другой стороны, обеспечивают новое видение общества, искусства, художников и помогают размышлять об этом. Научная новизна исследования заключается в комплексном лингвистическом анализе конкретных вербальных комментариев Дени Дидро к произведениям искусства. В результате доказано, что не существует тождественных семиотических систем, поскольку язык является интерпретантом всех знаковых систем.
\end{abstract}

\title{
EN Interrelation of Sign Systems: Verbal and Pictorial Languages (by the Example of Denis Diderot's “Salons”)
}

\section{Belova T. M.}

\begin{abstract}
The aim of the study is to determine the interrelation of verbal and figurative languages using the example of Denis Diderot's literary commentaries on works of art. The article provides the description of critical essays, the so-called Salons. The data obtained allow concluding that Diderot's Salons perform certain functions; on the one hand, they influence public opinion and shape morality, on the other hand, they provide a new vision of society, art, artists and help to reflect on this. The scientific originality of the research lies in a comprehensive linguistic analysis of Denis Diderot's specific verbal comments on works of art. As a result, it is proved that there are no identical semiotic systems, since language is an interpreter of all sign systems.
\end{abstract}

\section{Введение}

Проблема изучения знака, его видов и свойств, взаимодействия между различными знаковыми системами имеет междисциплинарный характер и является предметом современных гуманитарных исследований.

Актуальность данного исследования определяется многообразием языков описания мира и их соотношением. Такие языки, как вербальный язык и язык искусства, представляют собой исторически сложившиеся и особым образом организованные системы для репрезентации окружающей действительности. Соперничество между данными языками начинается еще в эпоху Возрождения и продолжается в современном мире.

Актуальность проблематики предопределила выбор объекта и предмета исследования. Объект исследования - отношения между вербальным и изобразительным языками как двумя семиотическими системами. Предмет исследования - функционирование изобразительно-выразительных средств вербальных комментариев Дени Дидро, посвященных картинам Жана-Батиста Шардена и Пьера-Антуана Бодуэна, как источник для понимания искусства XVIII века и образец формирования нового жанра - литературной критики.

Для достижения указанной цели исследования необходимо решить следующие задачи: во-первых, выявить и описать языковые образные средства, используемые автором для описания картины и воздействия на читателя, во-вторых, проверить гипотезу об эквивалентности между вербальным и изобразительным языками.

Теоретической базой исследования послужили труды ученых, в которых излагаются основные положения и тенденции семиотики, изучается роль вербального языка в отражении мира, рассматриваются вопросы 
о семиотическом анализе языков культуры и ее текстов (Р. Барт, Э. Бенвенист, В. фон Гумбольдт, Д. Локк, Ф. де Соссюр, У. Эко, М. М. Бахтин, Е. Е. Бразговская, А. Ф. Лосев, Ю. М. Лотман, Г. Г. Почепцов и др.).

Основным методом исследования является описательный, основанный на наблюдениях за языковыми образными средствами, их описании.

Практическая значимость исследования заключается в том, что материалы исследования могут использоваться в преподавании ряда филологических дисциплин, таких как лингвистика текста, семиотика, стилистика.

\section{Основная часть}

Дени Дидро - французский писатель, драматург, философ эпохи Просвещения. Роль искусства и литературы в эстетике Просвещения была очень велика. Самые близкие их сердцу идеи просветители высказывают в форме рассмотрения проблем искусства. Вопросам теории искусства Дидро посвятил очень много работ: от Энциклопедии, объединившей усилия всех передовых людей просветительного движения, до критических обзоров выставок, так называемых Салонов (Дидро, 1989, с. 8).

Королевская академия живописи и скульптуры проводит выставки в Квадратном салоне Лувра каждые два года. Дидро их посещает и пишет отчеты, опираясь только на каталоги и записи, сделанные во время визитов. Критические обзоры Дидро публикуются в рукописном журнале «Литературная корреспонденция» с 1759 по 1781 гг. Редактор журнала - друг Дидро, публицист, литературный критик, дипломат Фридрих Мельхиор Гримм. Тираж журнала не превышает 20 экземпляров. Цель журнала - распространение информации среди коронованных и титулованных особ европейских дворов об интеллектуальной и литературной жизни Парижа.

Читатели Салонов не видят произведения искусства. Дидро представляет их публике посредством словесного языка. Видится уместным вспомнить о приеме экфрасиса, уходящем своими истоками к древнегреческим риторическим упражнениям и олицетворяющем, по определению Дж. Хеффернана, словесное представление визуальной образности (Автухович, 2015). Гений Дидро заключается в нарушении традиционного экфрасиса, бывшего универсальным способом репрезентации произведений искусства. Дидро отходит от традиции описывать художественные произведения с целью восхваления, он оценивает их, исходя из своего эстетического вкуса.

Исследователь творчества Дидро, швейцарский филолог, литературный критик Жан Старобинский, выделяет следующие характеристики Салонов: картина, представленная Дидро, имеет не только визуальное измерение, но также тактильное, акустическое, вкусовое. Для Дидро-критика важна взаимосвязь эстетической и моральной ценностей искусства. Критик становится соперником художника, он создает словесный эквивалент картин и восклицает: «Я тоже художник». Жан Старобинский полагает, что для Дидро принципиальной разницы между воображаемой картиной, то есть написанной, и нарисованной нет (Buffat, 1993).

По утверждению Натали Кремер, Дидро является основоположником жанра художественной критики, контуры которого он намечает в своих Салонах, опубликованных только в XIX веке (Kremer, 2020).

Дидро посещает галереи, коллекции, мастерские художников, скульпторов, граверов для того, чтобы постичь секреты профессий и изучить терминологию живописи и скульптуры. Гита Мэй, специалист по французской литературе XVIII-XIX веков, особенно в области взаимосвязи между литературой и визуальными искусствами, отмечает, что в отличие от Вольтера, выступавшего за чистоту французского языка, Дидро в своих критических обзорах использует слова иностранного происхождения, обогащает язык неологизмами (Мау, 1970).

С целью изучить эстетическую сущность изящных искусств, Дидро погружается в изучение трактатов итальянского художника и изобретателя Леонардо да Винчи, французского историка искусств Андре Фелибьена, французского живописца и теоретика искусств Роже де Пиля, немецкого историка искусства Иоганна Винкельмана и других ученых.

В парадигме данного исследования базовым определением считаем утверждение Эмиля Бенвениста (1974) о том, что привилегированное положение языка заключается в его свойстве осуществлять одновременно и означивание знаков, и означивание высказывания. Отсюда и проистекает его главная способность, способность создавать второй уровень высказывания, когда становится возможным высказывать нечто означивающее о самом означивании. В этой метаязыковой способности и лежит источник отношения интерпретирования, благодаря которому язык включает в себя другие системы.

Н. Н. Грибова (2020) отмечает, что литературное произведение отличается от объекта искусства тем, что оно имеет вербальное выражение, фактуальная информация объекта искусства закодирована и опредмечена. Семантическое пространство литературного произведения является более насыщенным и неограниченным в интерпретационных возможностях. Структурный анализ вербального текста связан с выделением единиц различных уровней системы и описанием их функционирования. Но в визуальном изображении отсутствуют подобные дискретные элементы. Картина есть информационная знаковая структура, которая создается и прочитывается как текст, однако ее язык «выскальзывает из объятий» лингвистической методологии (Бразговская, 2019).

Отбор критических очерков для лингвистического анализа определяется двумя факторами. Во-первых, Салоны 1765 и 1767 годов являются вершиной критической деятельности Дидро (1989), они наиболее содержательны в теоретическом отношении, написаны с необычайной энергией и самые обширные (с. 10). «Это лучшее из того, что я сделал с тех пор, как занимаюсь литературой», - пишет Дидро Софи Волан по поводу Салона 1765 года (Diderot, 1930, с. 81). Во-вторых, композиционная структура и стилистическая тональность выбранных текстов раскрывают субъективное отношение Дидро к описываемым полотнам и их авторам, его ценностные установки и убеждения. 
25 августа 1765 года открывается выставка и продлевается до конца сентября по причине невероятного успеха. Экспозиция отмечена разнообразием - сорок художников и одиннадцать скульпторов представляют свои творения.

В центре нашего внимания - очерк, посвященный натюрмортам Шардена. Входит в Салоны 1765 года (Дидро, 1989, с. 129-132). Дидро начинает его с обращения к Шардену: Vous venez à temps, Chardin, pour récréer mes yеux que votre confrère Challe avait mortellement affligés. / «Вы, Шарден, появляетесь как раз вовремя, чтобы отдохнул мой взгляд, смертельно оскорбленный творениями Шалля». С помощью приёма гиперболизации mortellement affligés (смертельно оскорбленный) Дидро резко противопоставляет двух художников: Шардена и Шалля, тем самым создавая яркий положительный образ Шардена. По мнению Дидро, картина должна производить на зрителя самое сильное или самое приятное впечатление. Это именно случай Шардена. Употребление эпитета grand magicien (великий волшебник), восклицательных предложений (четыре из семи предложений первого абзаца - восклицательные) помогает критику передать чувства ликования и радости от созерцания натюрмортов художника. Автор восхищается цветовой гаммой, правдоподобием, прозрачностью полотен: l'imitation de la nature, la science de la couleur et l'harmonie (подражание природе, понимание колорита и гармонии); Comme l'air circule autour de ces objets! / «Как живо струится воздух вокруг ваших предметов!». Согласно Дидро, следующему платоновской модели искусства, задача художника заключается в точном изображении предметов и явлений реального мира. Художник не должен проявлять свою индивидуальность. Все это Дидро находит у Шардена и любуется: Vous revoilà donc... avec vos compositions muettes! / «Вы снова здесь... вместе со своими безмолвными созданиями!».

Восклицая и повторяя Chardin est si vrai, si vrai, si harmonieux / «Шарден столь правдив, столь правдив, столь гармоничен», Дидро оценивает по достоинству естественность, зримое присутствие перечисленных предметов. Критик использует приём сравнения, сопоставляя двух известных французских художников Верне и Шардена с целью демонстрации важных качеств Шардена: ...il se soutient et peut-être vous enlève à deux des plus beaux Vernets à côté duquel il n'a pas balancé de se mettre / ...«он выдерживает сравнение и даже отвлекает взоры от двух прекрасных работ Верне, рядом с которыми он не побоялся разместить свои натюрморты». Характеризуя полотна французского художника-пейзажиста Клода Верне, Дидро использует прилагательное bеаи (прекрасный) в превосходной степени, таким образом, акцентирует внимание читателя на своем восторженном отношении к его творчеству. С другой стороны, Дидро подчеркивает смелость и уверенность Шардена, который, являясь распорядителем выставки, размещает свои натюрморты рядом с картинами Верне.

Особое внимание в очерке Дидро уделяет характеристике жанровой живописи, формирующейся во второй половине XVIII века и представляющей собой важную ступень буржуазного французского искусства. Elle ne demande que de l'étude et de la patience, nulle verve, peu de génie, guère de poésie, beaucoup de technique et de vérité, et puis c'est tout. / «Она не требует ничего, кроме ремесла и терпения. Никакого воодушевления, немножко таланта, никакой поэзии, зато много техники и правды - вот и все». Через употребление ограничительного оборота ne ... que, наречия отрицания guѐre (почти не), оппозиции наречий количества peu/beaucoup (мало/много) Дидро настаивает на преимуществе в первую очередь техники художника и правды как основополагающих свойств данного вида живописи.

Во второй части комментария Дидро подробно останавливается на умении Шардена подбирать предметы для натюрмортов и великолепном знании цветовых отношений. Приведем несколько примеров:

Le peintre a répandu sur une table... une foule d'objets divers distribués de la manière la plus naturelle et la plus pittoresque. / «Шарден расположил на столе множество разнообразных предметов в самой естественной и самой живописной манере».

Combien d'objets! Quelle diversité de formes et de couleurs! et cependant quelle harmonie! / «Сколько предметов! Какое разнообразие форм и цветов! И притом, какая гармония!».

Cet homme est le premier coloriste du Salon et peut-être un des premiers coloristes de la peinture. / «Этот человек первый колорист Салона и, наверное, один из лучших колористов в живописи».

Дидро-критик позволяет читателю увидеть и оценить натюрморты Шардена при помощи вербального языка. Исходя из проведенного лингвистического анализа, можно заключить, что из широкого арсенала средств выражения французского языка Дидро выбирает такие средства, как метафоры, сравнения, эпитеты, риторические восклицания, антитезы, лексические повторы. Наличие эмоционально-окрашенных слов, большое количество прилагательных и наречий, усовершенствованный синтаксис также характеризуют вербальный язык эссе. Все перечисленные стилистические и грамматические приемы привлекают внимание читателя к основным понятиям, структурно организуют текст, оказывают эмоциональное воздействие на адресата. Дидро внушает читателю, что всё совершенно у Шардена: цветовая гамма, композиция, правдоподобие, невидимость художника. Все эти элементы соответствуют миметической концепции искусства, которой придерживается Дидро-философ.

Резюмируя вышесказанное, отметим, что, с одной стороны, Дидро, являясь философом, размышляет об искусстве через призму метафизической картины мира. С другой стороны, он умеет смотреть картины. Вслед за французским теоретиком искусства Роже де Пилем, Дидро обращает внимание читателя на вопросы цвета, цветотени, правдоподобия, техническое мастерство художника.

Очерк, посвященный картине Пьера-Антуана Бодуэна, входит в Салоны 1767 года (Дидро, 1989, с. 109-111). Пьер-Антуан Бодуэн - французский художник-миниатюрист, мастер гуаши.

Дидро начинает очерк следующим образом: Toujours petits tableaux, petites idées, compositions frivoles, propres au boudoir d'une petite-maîtresse, à la petite maison d'un petit-maître, faites pour de petits abbés, de petits robins, de gros 
financiers ou autres personnages sans mœurs et d'un petit goût. / «Все те же маленькие картины, мелкие идеи, фривольные композиции, пригодные для будуара модницы или укромного приюта щеголя, писанные для игривых аббатов, мелких дельцов, денежных тузов и прочих лиц, лишенных добрых нравов и наделенных незначительным вкусом».

С точки зрения синтаксической организации - это односоставное номинативное утвердительное предложение с однородными членами, а также с обособленными и необособленными определениями, выраженными причастными оборотами. Предложение начинается с наречия toujours (всегда), характеризующего постоянство и статичность всех описываемых далее характеристик творчества художника. Все фонетические, стилистические и грамматические приемы: лексические повторы (прилагательное petit/e - маленький - повторяется в предложении восемь раз), сниженная лексика (frivoles (фривольные), boudoir (будуар), un petit-maître (щёголь)), метафорические эпитеты (petites idées (мелкие идеи), petit goût (незначительный вкус)), наречие sans (без), прием аллитерации, - формируют у читателя сомнительный образ Бодуэна, демонстрируют отрицательное отношение Дидро к нему. Все маленькое и незначительное у этого художника: его картины, его идеи, его вкус. Он работает для людей без морали, не имеющих никакой важности.

Можно сделать вывод о том, что организация данного предложения тщательно продумана автором и подчинена созданию соответствующего художественного образа художника. Экспрессия односоставного номинативного предложения содержит разнообразные изобразительные возможности, позволяющие читателю войти в мир художественного текста и понять замысел Дидро-критика.

Далее автор приглашает читателя войти в квартиру и увидеть происходящее. Его описания очень тщательные и детальные. Употребление настоящего времени изъявительного наклонения, наречий места à droite (справа), devant (перед), derrière (за, позади), au côté de (около), à gauche (слева), дейктических указательных местоимений ce/cet/cette (этот/эта), celle-ci (эта, вот та) служит для актуализации описаний. Дидро создает эффект мгновенности и одновременности для усиления иллюзии присутствия описываемого. Картина представляется читателю как зрителю.

Дидро обращается к художнику, спрашивая, где могла происходить изображенная сцена и в чем её предназначение. Он упрекает Бодуэна в выбранном моменте, утверждая что «Ce moment est faux. Il serait vrai qu'il serait d'un mauvais choix». / «Изображенная Вами сцена ложна. Будь она правдоподобна, она свидетельствовала бы о неудачном выборе». Употребление отрицательно-коннотированных прилагательных faux (ложный) и mauvais (плохой) демонстрирует значимость сюжета и сцены картины для Дидро-критика.

Используя пример французского живописца Жана-Батиста Грёза, автор предлагает читателю вариант написания картины художником. Грёз восхищает его своим выбором соответствующего момента и художественным воплощением образа. Он восклицает: «Quelle tendresse! Quelle honnêteté! quelle délicatesse! quelle variété d'actions et d'expressions dans les frères, les sœurs, les parents, les amis, les amies, quel pathétique n'y aurait-il pas mis». / «Какую нежность, какое целомудрие, какую чувствительность, какое разнообразие действий и выражений придал бы он братьям, сестрам, родственникам, друзьям и подругам! Сколько возвышенности вложил бы он в эту сцену!». Вслед за французским историком искусства Андре Фелибьеном, Дидро полагает, что композиция, выбор взглядов, движений тел, душевных чувств должны служить выражению высоких чувств, что отсутствует в полотнах Бодуэна.

По мнению критика, идеалом в данном контексте была бы новобрачная, окруженная матерью, отцом и близкими родственниками. Описывая картину Бодуэна, Дидро использует метафорические эпитеты и сниженную лексику для выражения своего раздражения и неприятия полотна (la petite mine chiffonnée / помятая мордочка; ces indignes creatures / недостойные твари; une courtisane / куртизанка; un petit libertin / жалкий распутник). Выбранная художником манера письма нарушает идеал. Картина должна производить на зрителя самое приятное впечатление, все должно быть совершенным. Этого нет у Бодуэна.

Вторя часть эссе представляет собой философские рассуждения о морали. Как и Роже де Пиль, Дидро видит высокое предназначение искусства. Для него «les mœurs sont essentielles au bon goût» (хороший вкус немыслим без добрых нравов). Он советует художникам de «tenir aux sujets honnêtes» (придерживаться чистых сюжетов). Прослеживается конфронтация между Дидро-метафизиком и Дидро - любителем искусства. Дидро пытается рационализировать искусство. На уровне лексики автор противопоставляет нравственные понятия la probité (честность, порядочность), la vertu (добродетель), l'honnêteté (честность), le scrupule (совестливость) таким понятиям и предметам, как corruption d'un cœur innocent (совращение невинного сердца), un mauvais livre (безнравственная книга), une estampe malhonnête (непристойная гравюра), des imaginations perdues (расстроенное воображение), un mélange inexplicable de corruption et de barbarie (необъяснимое смешение испорченности и разврата).

Только в последнем абзаце Дидро возвращается к художнику и останавливается на самых важных элементах живописи с точки зрения Андре Фелибьена: композиции, рисунке, цвете. Он одобряет только великолепно написанную фигуру и лицо новобрачной. Все остальное - посредственно: «La couleur est terne; et tout est gris» (Цвет - блеклый; все - серое).

Очевидно, что в данном литературном комментарии наиболее полно проявились все стороны таланта Дидро как писателя (он нарушает границы художественного объекта, входит в картину, предлагает свой вариант написания картины и вариант художника Грёза), философа (размышляет о чистоте искусства, нравах общества, таким образом, отходит от своей первоначальной задачи - описания картин для журнала), энциклопедиста (демонстрирует свои глубокие знания вопросов античной и современной скульптуры, истории) и критика. 


\section{Заключение}

В результате проведенного исследования мы пришли к выводу, что вербальный и изобразительный языки не являются и не могут быть эквивалентными. Язык есть интерпретант всех других семиотических систем как лингвистических, так и нелингвистических.

Пример Дидро показывает, как картина становится отправной точкой для создания литературного шедевра. Из сказанного становится очевидным то, что вербальный язык не может все охватить и передать. Дидро пытается установить связь между литературой и изобразительными искусствами, создавая особый новый для своей эпохи жанр литературной критики, который продолжает в XIX в. Шарль Бодлер. Дидро имеет свою концепцию искусства. Салоны - это очерки, в которых он наблюдает, указывает, восхищается, ненавидит. Его позиция всегда противоречивая. За каждым его суждением стоит собственная философская система мышления. Вербальный язык всегда остается проводником между читателем и произведением искусства.

В перспективе видится интересным обратиться к вопросу развития художественной критики в XIX веке во Франции на примере критических работ Шарля Бодлера в качестве художественного критика для Салона 1845 года, а также сравнить основные позиции, манеру письма, анализа двух основоположников жанра Дени Дидро и Шарля Бодлера.

\section{Источники | References}

1. Автухович Т. Е. Экфрасис как жанр и/или дискурс // Диалог согласия: сборник научных статей к 70-летию В. И. Тюпы / ред. О. В. Федунина, Ю. Л. Троицкий. М.: Intrada, 2015.

2. Бенвенист Э. Семиология языка // Бенвенист Э. Общая лингвистика. М., 1974.

3. Бразговская Е. Е. Семиотика. Языки и коды культуры. М.: Юрайт, 2019.

4. Грибова Н. Н. Концептуальное пространство художественного текста в аспекте теории нечетких множеств. Модель эстетического восприятия произведения искусства. М. - Берлин: Директ-Медиа, 2020.

5. Дидро Д. Салоны: в 2-х т. М.: Искусство, 1989. Т. 1.

6. Дидро Д. Салоны: в 2-х т. М.: Искусство, 1989. Т. 2.

7. Buffat M. Jean Starobinski, Les Salons suivi du Sacrifice en rêve. 1993. URL: https://www.persee.fr/doc/rde_07690886_1993_num_14_1_1212

8. Diderot D. Lettres a Sophie Volland: 3 vol. / textes publiés par A. Babelon. Paris: Gallimard, 1930. Vol. II.

9. Kremer N. Les lignes brisées de l'art. Diderot et Baudelaire devant la peinture. 2020. URL: https://www.cairn.info/ revue-nouvelle-revue-d-esthetique-2020-1-page-145.htm?contenu=resume

10. May G. Diderot et Roger de Piles. 1970. URL: https://www.jstor.org/stable/1261446

\section{Информация об авторах | Author information}

RU Белова Татьяна Мухорамовна ${ }^{1}$, к. филол. н., доц.

${ }^{1}$ Санкт-Петербургский государственный институт кино и телевидения

EN Belova Tatiana Mukhoramovna ${ }^{1}, \mathrm{PhD}$

${ }^{1}$ St. Petersburg State University of Film and Television

${ }^{1}$ tatbel42@mail.ru

\section{Информация о статье | About this article}

Дата поступления рукописи (received): 29.08.2021; опубликовано (published): 29.10.2021.

Ключевые слова (keywords): Д. Дидро; Салоны; вербальный язык; изобразительный язык; эквивалентность между знаковыми системами; D. Diderot; Salons; verbal language; pictorial language; equivalence between sign systems. 